\title{
Sorbitol Dehydrogenase Measurement
}

National Cancer Institute

\section{Source}

National Cancer Institute. Sorbitol Dehydrogenase Measurement. NCI Thesaurus. Code C79465.

The determination of the amount of sorbitol dehydrogenase present in a sample. 